\title{
Study on Theory Construction of Sports Information Management and Development of Application Systems
}

\author{
Guan Duohong ${ }^{1, a}$ \\ ${ }^{1}$ Sports Department of Sichuan Panzhihua University, Panzhihua in Sichuan province, China, \\ 617000 \\ aguanduohong@163.com
} Keywords: sports information management; theoretical construction; application systems
development

\begin{abstract}
In sports management, the information can be used as a means of education and also as an object of education and is essential in any physical education activities. In educational activities, as a manager and decision-makers of activities, information can help organize personnel establish an important basis, and the whole process of sports management are constantly process and application of information. To better improve the effectiveness of physical education information and separate sports information from the emerging discipline for an important research, which is also a contribution to China's development in global economy and Olympic sports, at the same time promote the development of China's sports education colleagues and achieve new processes of sports information services industry.
\end{abstract}

\section{Introduction}

The main role of sports information management is to overall contribute to sports information resource development. In order to make better use of the role of information in the event management, adequately and effectively develop and utilize resources in physical activity, to achieve this goal, use more methods and technology to improve and implement sports information management theory. in sport to information management theory.

\section{Theoretical Construction of Sports Information Management}

The basic essence of sports information management is one of fundamental theoretical issues in sports information management, and the in-depth study of sports information pedagogy theoretical issue deepening is also one of the deepening research. On the basis of the background investigation of sports information management and the investigation of research subjects, physical education management starts his own independent pace step by step and is no longer dependent on modern physical education management and sports science.It can be said that sports information management is not a separate discipline and it is cross. Cross-discipline is also called interdisciplinary, ie, sports information management disciplines is arising among the fields of sports education or other disciplines edges and also is an important way of the formation of a new species in the scientific disciplines. Of course, not just sports information management discipline is generated in this way and other disciplines are also generated in such a way, sports information management is the discipline derived from a variety of subject edge like sports science, information science EPRI and management, information technology, etc., whose cross-cutting nature can be represented by the following diagram (Figure 1). The sports information management science develops built on the original information science, which not only has advantages of information theory and systems theory and also other control methods and theories, which absorbs the advantages of existing disciplines and owns the basic theory and the practical support.

Management platform itself has realized framework model of a universal platform plus plug-in software development, that this thinking way and the design method has proved feasible through practice and can be applied to specific software development. By this way we can well solve the software collaborative development and integration issues and is more useful on software owning 
version level. The advanced version software is installed with advanced version of the plugin, a lower version of the software is not installed the advanced version of the plugin, which brought great convenience to program distribution and development. For system functions software, systematic functions are implemented by plug-in. We have become accustomed to developing software independently. Everyone uses their own style of programming, but with project becoming larger or the more closely time requirements, we need a few people, a dozen people and even hundreds of people cooperatively develop and design software. Then a relative difficult problem is how to seamlessly integrate the software code (may be a link library, component). The source code integration is a relative traditional and mature manner and the appropriately use of link library or component can also reduce the leakage of the source code, but the case is often that every program integration or code maintenance need second compile and link source code and re-release new software, which sometimes is very troublesome. Then there is the question, whether there is a way can divide target software needing to develop into several functional parts and each part follows a standard interface between such provisions. After the development of various parts according to the requirements, needed components were integrated but not integrating the source code or link library to compile and link, needed new functionality is developed according to requirements and can be used only after the assembly software to use, which is software integration method using binary. That is platform + plug-ins software design method.To deeply understand sports information management activities, related activities are many, thus inevitably many disciplines involved to support research and training of sports information management disciplines. To study sports information management should also collect information economics and psychology law, mathematics and other disciplines information, and sports information management not only has the complexity but also the particularity, because sport is information gathering for the human body itself and is closely related with the information obtained in sports and training, and the ways and means of information collection need to provide special facilities.

Therefore, to deeply understand the complex nature of sports information management, the in-depth study of the various aspects of collection of related information and theories of other disciplines to promote the research and development of sports information management. Use Euler identity: $\mathrm{e}^{\wedge}(\mathrm{i} \pi)+1=0$

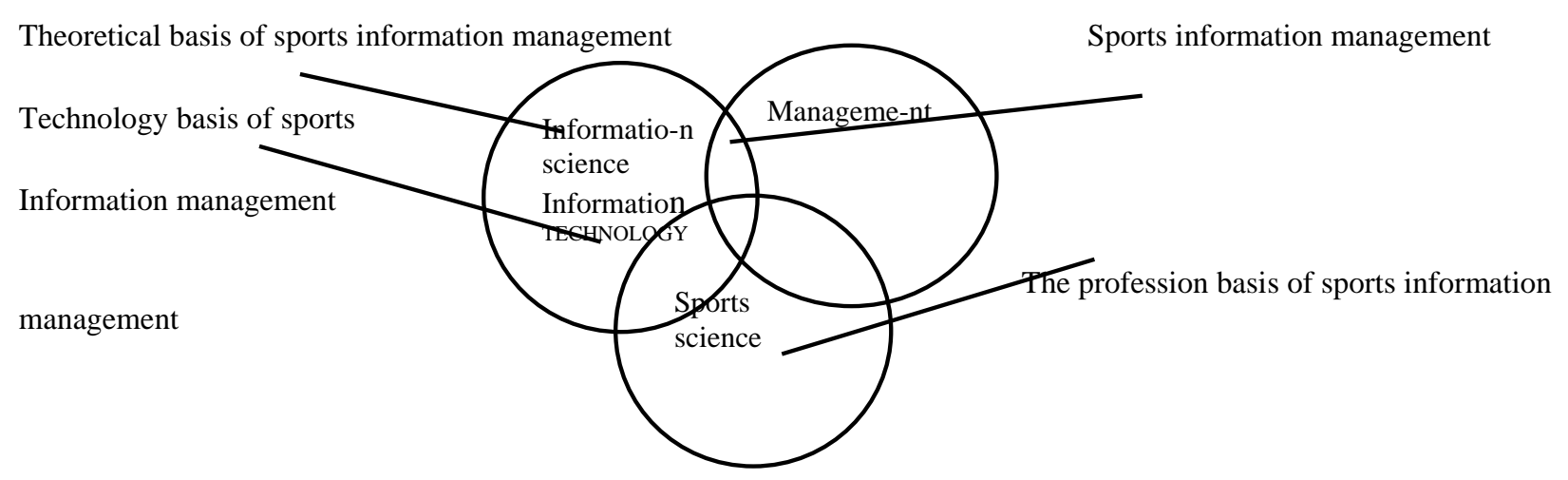

Figure 1 Complex nature of sports information management

$\mathrm{E}$ is the bottom of natural index, $\mathrm{i}$ is the imaginary unit and $\pi$ is pi, which respectively represent management, sports science and information science and information technology and get excellent cross calculated nature. 


\section{Application systems development of sports information management}

In knowledge economy era, knowledge updates fast. According to statistics, in recent ten years, the fast development of scientific technology rapidly improved the development of sports education science and the improvement of labor technology level. Knowledge and technology got common use and development, which brought greater developing space for the development of sports science and sports science knowledge is gradually strong, which symbols the increase of sports information number.

\begin{tabular}{rrrrrrrrrrrrrr}
\hline Year 1932 & 1935 & 38 & 43 & 47 & 51 & 53 & 56 & 63 & 66 & 68 & 72 & 74 & $80-$ \\
\hline Number 87 & 87 & 93 & 80 & 89 & 96 & 134 & 161 & 198 & 262 & 432 & 669 & 1012 & 5000
\end{tabular}

Currently, people have entered into information covering era. In social resource, information, material and energy have become the main components and the development and use have become the primary task. While the development of information technology and the reformation and task on information resource development turn into the information management, thus form the information systems. Currently, the use and development of information system involved industries are mainly finance, industry, business management and other services and government. In essence, management means that coordinate the object of internal and external resources and plan to get system effect. So management level and effect management process information closely related with the use level. Thus sports information is the core of every management content. And information management plays an important role.

In network development, both those industries and government management work are affected. The original single mode is turned into LAN, then into WAN and finally is able to overall statistic the country's system and unit information, which greatly improve the efficiency of enterprises and make the distribution and integration of data possible

\section{References}

[1] Li Dongzhu. Theory and Applications of Management Information System [M]. Peking University Press, 2001

[2] Zuo Meiyun, Kuang Kongwu. Information Systems Development and Management Course [M]. Tsinghua University Press, 2001

[3] Feng Jianwei. The Information New Theory [M]. Xinhua Publishing House, 2001

[4] Wang Qun, Li Fujuan. LAN Alike [M]. Ocean Press, 2001

[5] Yan Fei. Software Engineering [M]. China Water Resources and Hydropower Press, 2001 